\title{
Subacute thyroiditis during pregnancy
}

\section{CananYlddız 2. Mustafa Altay}

\section{Introduction:}

Hyperthyroidism during pregnancy is a rare condition and occurs in 0.1 to $0.4 \%$ of all pregnancies ${ }^{1}$. Graves' Disease and transient gestational thyrotoxicosis constitute the majority of emerging thyrotoxicosis during pregnancy ${ }^{2,3}$. Subacute thyroiditis (SAT) may also cause temporary hyperthyroidism. Nevertheless, only a few SAT cases reported occurring during pregnancy ${ }^{4}$.

\section{Case report:}

A thirty-three-year-old, 13-week pregnant patients was admitted with fatigue, pain and swelling in thyroid lodge. Thyroid function tests performed two months ago were found to be in the normal range. On physical examination of the patient, there was no symptoms other than pain in the neck, and bilateral thyroid gland was large with tenderness. The laboratory tests carried out at the patient's admission are in Table 1. In the thyroid USG both lobes were large and parenchymal blood flow was not increased. There was a distinct view of bilateral subacute thyroiditis and reactive bilateral cervical lymphadenopathy. Paracetamol 3x500 mg was started because of the pain. The patient's pain was significantly decreased 3 days later. Clinical and laboratory findings in patient was compatible with SAT. 10 days later, pain and tenderness in the thyroid lodge was completely relieved. After repeated laboratory tests, $50 \mathrm{mcg}$ of levothyroxine was instituted. With levothyroxine treatment, patient did not experience any problem during pregnancy and when she was 38 weeks and 2 days pregnant, vaginally delivered a healthy baby boy who weighs $3740 \mathrm{gr}$.

\section{Discussion:}

SAT is a condition characterized by neck pain, diffuse tenderness in thyroid lodge and changes in thyroid function ${ }^{5}$. Viral infections and post-viral inflammatory process are thought to play a role in the pathogenesis ${ }^{6}$.

There are very few cases in the literature of SAT occurring during pregnancy. The first case was reported by Hiraiwa et al in $2006^{7}$. SAT has been determined in two cases who are 35 and 31 years old and respectively 11 and 6 weeks pregnant ${ }^{7}$.A similar case was reported by Anastasilakis et al in $2011^{8}$. Case, who was 30 years old, presented with SAT in 6th week of the pregnanacy ${ }^{8}$.

Regardless of the pregnancy, SAT is seen most frequently in the 28-30 and 40-50 age ranges ${ }^{9,10}$. It has been found that seasonal changes play role in the presence of SAT (more seen in March and August) but statistical significance could not be determined ${ }^{6,11}$. This supports the hypothesis that viral infections play role in the pathogenesis.

Although it is rare when compared to other diseases occurring in the first trimester of the pregnancy, hyperthyroidism may lead to serious complications such as prematurity, low birth weight and eclampsia ${ }^{12,13}$. Thyrotoxicosis in pregnancy, occurs at the average rate of $1-4$ per 1000 pregnancies $^{2,3}$. If it is assumed that subacute thyroiditis is responsible for $1 \%$ of the whole thyrotoxicosis cases, $10-40$ SATs are expected to be occur in each 1.000 .000 pregnancies $^{7}$.

There are two main objectives in the treatment of patients; i.e. pain control and correcting the effects of thyrotoxicosis. NSAIDs and prednisone are used for pain control and the prevention of inflammation ${ }^{14}$. Thyroid peroxidase inhibitor is not recommended in the treatment of thyrotoxicosis but beta-blockers (propranolol, atenolol) can be used for the suppression of the symptoms ${ }^{15}$. Although most of the patients remain euthyroid after exacerbation, hypothyroidism is likely to develop and in these patients levothyroxine treatment can begin temporarily ${ }^{15}$.

Table 1. The course of thyroid function tests and LT4 treatment

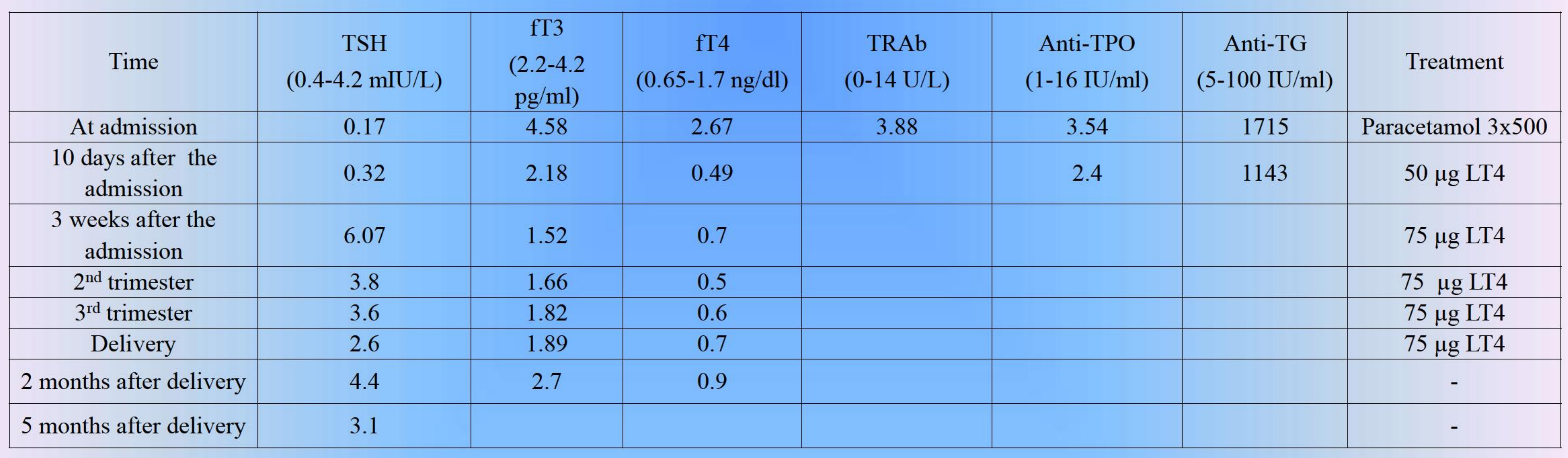

\section{Conclusion:}

When determining the differential diagnosis of thyrotoxicosis in pregnancy, subacute thyroiditis should also be considered and detailed history and physical examination of the thyroid should not be neglected. Although the majority of the patients recover without treatment, complications in the pregnancy should be borne in mind and each patient must be evaluated individually.

References:

Krassas GE, Poppe K, Glinoer D. Thyroid function and human reproductive health. Endocr Rer. 2010;31(5):702755. doi: 10.1210/er.2009-0041.

Becks GP, Burrow GN. Thyroid disease and pregnancy. Med Clin North Am. 1991;75(1):121-150. http://www.ncbi.nlm.nih. gov/pubmed/1987439. Accessed August 31, 2015.

Wang C, Crapo LM. The epidemiology of thyroid disease and implications for screening. Endocrinol Metab Clin North Am. 1997;26(1): 189-218. http:// www.ncbi.nlm.nih. gov/pubmed/9074859. Accessed June 25, 2015. Werner \& Ingbar's the Thyroid:A Fundamental and Clinical Text, 549. Cilt.; 2005

https://books.google.com/books?hl=tr\&lr=\&id=HoOm6PuNcwwC\&pgis=1. Accessed August 31, 2015. Subacute thyroiditis. http://www.uptodate.com/contents/subacute-thyroiditis. Accessed August 31, 2015. Martino E, Buratti L, Bartalena L, et al. High prevalence of subacute thyroiditis during summer season in Italy. J Endocrinol Invest. 1987;10(3):321-323. doi:10.1007/BF03348138.

Hiraiwa T, Kubota S, Imagawa A, et al. Two cases of subacute thyroiditis presenting in pregnancy. J Endocrinol Inves. 2006;29(10):924-927. doi:10.1007/BF03349198.

Anastasilakis AD, Karanicola V, Kourtis A, et al. A case report of subacute thyroiditis during pregnancy: difficulties in differential diagnosis and changes in cytokine levels. Gynecol Endocrinol. 2011:27(6):384-390. doi:10.3109/09513590.2010.493963.
9. Fatourechi V, Aniszewski JP, Fatourechi GZE, Atkinson EJ, Jacobsen SJ. Clinical features and outcome of subacute thyroiditis in an incidence cohort: Olmsted County, Minnesota, study. J Clin Endocrinol Metab. 2003;88(5):2100-2105. doi:10.1210/jc. 2002 021799

10. Golden SH, Robinson KA, Saldanha I, Anton B, Ladenson PW. Clinical review: Prevalence and incidence of endocrine and metabolic disorders in the United States: a comprehensive review. J Clin Endocrinol Metab. 2009;94(6):1853-1878. doi: 10.1210/jc.2008-2291.

11. Dulipsingh L, Ikram Z, Malchoff CD, Shoukri KC. A cluster of cases of subacute and silent thyroiditis in the northern Connecticut, Greater Hartford area. Conn Med. 1998;62(7):395-397. http://www.ncbi.nlm.nih.gov/pubmed/9707794. Accessed October 26 , 2015.

12. Millar LK, Wing DA, Leung AS, Koonings PP, Montoro MN, Mestman JH. Low birth weight and preeclampsia in pregnancies complicated by hyperthyroidism. Obstet Gynecol. 1994;84(6):946-949. http://www.ncbi.nlm.nih.gov/pubmed/797047 Accessed September 2, 2015.

13. Anselmo J, Cao D, Karrison T, Weiss RE, Refetoff S. Fetal loss associated with excess thyroid hormone exposure. JAMA. 2004;292(6):691-695. doi:10.1001/jama.292.6.691.

14. Yamamoto $M$, Saito $S$, Sakurada $T$, et al. Effect of prednisolone and salicylate on serum thyroglobulin level in patients with subacute thyroiditis. Clin Endocrinol (Oxf). 1987;27(3):339-344. http://www.ncbi.nlm.nih.gov/pubmed/3427792. Accessed September 3, 2015.

5. Hennessey JV. Subacute Thyroiditis. April 2015. http://www.ncbi.nlm.nih.gov/books/NBK279084/. Accessed September 3, Henness. 